\title{
The Identification of Cultural Diversity Factors in Swaziland's Public Schools
}

\author{
Mr Zaheer Hamid \\ Management College of South Africa, South Africa. \\ Zaheer.Hamid@mancosa.co.za \\ Prof Christo Bisschoff \\ Potchefstroom Business School, North-West University, South Africa. \\ christo.bisschoff@nwu.ac.za \\ Prof Christoff Botha \\ Potchefstroom Business School, North-West University, South Africa \\ christoff.botha@nwu.ac.za
}

\section{Doi:10.5901/mjss.2014.v5n23p540}

\section{Abstract}

\begin{abstract}
Swaziland is a small country situated in-between South Africa and Mozambique towards the southern tip of Africa. A former British colony Swaziland has a history of colonial education based on colonial interests and built on diverse education in the past. This study focuses specifically on cultural diversity in the Swaziland education sector and the management thereof. In doing so the cultural diversity factors that prevail in the Swaziland education sector are identified based on theoretical and empirical research. Swaziland achieved independence in 1968 upon which history documents its educational policy reform to a more inclusive, equal and progressive education regime. The present Swaziland education sector has evolved in shape and size and the current teacher workforce profile in Swaziland consists of both local and regional (African) teachers. This in itself creates an atmosphere of diversity: in this case cultural diversity. Success in managing teacher provisioning, development and management and evaluation of education provisioning requires an acute sensitivity to many managerial elements including that of cultural diversity. Five cultural diverse management factors have been identified. They are Cultural bias, Cultural tolerance, Cultural association, Cultural Inequality and Cultural minorities. These factors explain a satisfactory cumulative variance of $55 \%$, but have a lower order reliability as measured by Cronbach Alpha $(<0.60)$. The factors also do not correlate significantly with one another, indicating that the factors identified are individualistic in nature and should be managed as individual factors. The results are of value to education managers in Swaziland (and elsewhere), academia, and to future researchers.
\end{abstract}

Keywords: Cultural diversity, inequality, Swaziland, education management, public schools, cultural factors,

\section{Introduction}

Globally diversity is re shaping the way the world is populated and the way the world is perceived. An important diversity element within concept of diversity in the global workforce is cultural diversity. Cross cultural team functioning and collaborative functioning is vital for organizations to succeed (Vidhi, 2012).

Globally organizations are becoming more culturally diverse as a result of labour migration, globalization, and national and international skill demands. As a result of this; managing cultural diversity becomes a critical area of management functioning. This study seeks to explore the cultural diversity factors that may be considered when functioning within the Swaziland education sector.

Rijamampianina and Maxwell (2002) indicate that globally economic activity is fast pace and that effective responses from managers are required in the time of fast paced economic activity. Rijamampianina and Maxwell (2002) however also states that whilst there exists academic literature on the vitality of multi cultural management there exists is a degree of uncertainty about the application of multi cultural management and its outcomes primarily since the philosophy behind the application was based on unfounded assumptions of the area of multi-culturalism.

According to Tervonen (2012) it is critical for managers to have the social skills when managing an increasingly diverse workforce as managing diversity may create a more competitive workforce. Bolen and Kleiner (2013) argues that 
changing demographics of societies means changing workplace diversity and that organizations that do not recognize this risks the possibility of failure in the future as managing diversity is a business function and not just a social or moral one. Resultantly, the workplace requires diversity management skills which are crucial in effective of business leadership in modern organisations.

\section{Problem Statement}

The workforce found in Swaziland education sector is diverse in mother tongue, tribal origins, nationality and religious backgrounds. The people of Swaziland generally fall into three tribes, the Nguni which is the main clan or tribe whilst the minorities are made up of the Sotho and Tsonga. IsiSwati is the national language is Swaziland, however there are many other languages used including the eleven official languages of South Africa as well as to a lesser degree Chewa (or Nyanja) the national language of Malawi (Lewis, Simons \& Fennig, 2014).

Primarily, it is important to note that indigenous cultural differences exist within the peoples of Swaziland. In addition, the Swaziland school education sector also employs non-Swaziland citizens from South Africa, Zimbabwe, to assist with the need for qualified educators in the schooling system. As a result the Swaziland education sector has unique cultural diversity elements pertaining to the environment of the Swaziland education sector.

According to Deputy Director General of Education in Swaziland, Dr Sibongile Dlamini, this cultural diversity has never been formally studied, nor effectively managed within Swaziland education sector. Furthermore, a guideline or framework that considers cultural diversity management as an element of management within the spectrum of management of the education sector in Swaziland does not exist (Dlamini, 2013).

Research into Swaziland school education could, therefore, improve the management of efficiency and of this sector.

\section{Objectives}

\subsection{Primary objective}

The primary objective is to study cultural diversity in the Swaziland School Education Sector.

\subsection{Secondary objectives}

The primary objective is serviced by the following secondary objectives, namely to:

- Perform a literature study on cultural diversity;

- Empirically determine the sample adequacy;

- Empirically determine if the data is suitable for multivariate statistical analysis;

- Identify the managerial factors of cultural diversity;

- Determine the reliability of the factors; and to

- Discuss and offer recommendations on the management of cultural diversity.

\section{Theoretical Review of Cultural Diversity}

\subsection{Defining cultural diversity}

It is difficult to formulate an accurate and concise definition of cultural diversity. Firstly, it is behavioural, while secondly, it also contains aspects such as the environment, upbringing and tribal following. In addition, there are a number of concepts that are synonymous to cultural diversity. The issue of language and communication is a strong underlying contributor to cultural diversity. Holden (2001) indicates that "Language is a trap' spoken language is a means to communication, Communication however have nuances that are unique to a particular group. Words, body language, semantics, proxemics, kinesics, tone and choice of register all have differing comprehension amongst different language groups and societies.

Historically, the researcher Cox (1993:112) defined cultural diversity as: "an affiliation of people who collectively share certain norms, values or traditions that are different to those of other groups." Cox added that, "cultural diversity means the representation, in one social system, of people with distinctly different group affiliations of cultural 
significance". A later approach to cultural diversity, according to Drafke and Kossen (2002:56), is "a variety in beliefs, value systems, behaviour patterns, and thought characteristics." This definition stressed the beliefs and behavioural elements of importance in cultural diversity. A definition and understanding of culture offered by Dunmark (2005) is that "culture is an intangible and more akin to an experience" It is suggested that culture dictates how we perceive the world and people around us. It is not genetic but based on social engineering."

Both the definitions by to Drafke and Kossen (2002) and Dunmark (2005) indicates that there are common elements to found such as the perceptions and subsequent behaviours based on these perceptions. Donnelly et al. (2012:92) explain diversity in culture to be a "term to describe the cultural, ethnic and racial variations in a population."

However, the modern and elementary approach by the esteemed Oxford Dictionary signifies that a core definition of cultural diversity could yield a better understanding thereof. According to Oxford Dictionaries Online (2014), cultural diversity can simply be defined as "The existence of a variety of cultural or ethnic groups within a society".

From these definitions of culture diversity, also taking into account their augmentation over time, it is clear that a concise scientifically accepted definition for such an amorphous concept is difficult to achieve. Over time, however, some elements of the definitions are congruent namely that perceptions of the world and perceptions of peoples are based on one's own framework of reference. This reference framework is shared within a specific population (community) where a social system of cohesiveness is shared amongst people within this population. Resultantly this population employs a similar frame of reference and perceives the world and people similarly (which is a means of social engineering that took place by grouping people together). Hence the existence of cultural diversity is born.

\subsection{An overview of recent theories on cultural diversity}

\subsubsection{Theory 1: Hofstede}

Geert Hofstede is a renowned contributor of knowledge on culture and workplace influence. Essentially Hofstede says that culture is "collective programming or software of the mind" Mullins (2010:27-28). This view is akin to the definitions provided earlier. Hofstede advocates a Five Dimensions of culture framework as cited in Hamid (2014:5). It is a framework of functioning as a result of a collective engineering of the mind. The table below provides an overview of Hofstede's Five Dimensions of culture framework.

Table 1: Hofstede's Five Dimensions of Culture Framework

\begin{tabular}{|l|l|}
\hline Dimension & Explanation \\
\hline Power distance & $\begin{array}{l}\text { An element used to order levels of inequality in organizations dependent on management style, } \\
\text { willingness of subordinates to disagree with superiors, educational level and roles. }\end{array}$ \\
\hline Uncertainty Avoidance & The extent to which members of a society feel threatened by unusual situations. \\
\hline Individualism & Describes the relatively individualistic or collective ethic in that particular society. \\
\hline Masculinity & $\begin{array}{l}\text { Refers to the continuum between masculine characteristics such as assertiveness and competitiveness } \\
\text { and feminine traits such as caring, a stress upon the quality of life and concern with the environment. }\end{array}$ \\
\hline $\begin{array}{l}\text { Confucian work } \\
\text { dynamism }\end{array}$ & $\begin{array}{l}\text { Long term/short term orientation with regards to tradition and concern with the effect of actions and } \\
\text { policies on future generations }\end{array}$ \\
\hline
\end{tabular}

Adapted from Huettinger, (2008)

\subsubsection{Theory 2: Trompenaar}

Fons Trompenaar, also a contemporary of Hofstede, is a contributor of knowledge to the study of culture and differences. Trompenaar produced a framework which identifies seven areas in which cultural differences may affect aspects of organisational behaviour (Mullins, 2010:29). The table below demonstrates Trompenaar's framework 
Table 2: Trompenaar's Framework Of Cultural Differences

\begin{tabular}{|l|l|}
\hline Area & Explanation \\
\hline Relationship and rules & $\begin{array}{l}\text { This area speaks of how societies view rules as either a rigid view and subsequent behavior or flexibility } \\
\text { towards rules as a result of importance of relationships. }\end{array}$ \\
\hline $\begin{array}{l}\text { Societies - Individual or } \\
\text { collective }\end{array}$ & $\begin{array}{l}\text { This area speaks of societies taking a collective or individual orientation. The implication of responsibility } \\
\text { becomes real. }\end{array}$ \\
\hline $\begin{array}{l}\text { Neutral and Emotional } \\
\text { societies }\end{array}$ & The difference between societies in showing emotion in public. \\
\hline $\begin{array}{l}\text { Diffuse and specific } \\
\text { cultures }\end{array}$ & $\begin{array}{l}\text { This area speaks of the extent of involvement in a business relationship. The diffuse approach will involve } \\
\text { the whole person while the specific culture business relationship will be limited to the contractual limits. }\end{array}$ \\
\hline $\begin{array}{l}\text { Achievement versus } \\
\text { ascription of success }\end{array}$ & $\begin{array}{l}\text { Some societies (achievement) views success as an overall record of achievement whilst some (ascription) } \\
\text { views achievement and status as a result of bestowment of status through factors like age, gender and } \\
\text { educational levels. }\end{array}$ \\
\hline Societies view of time & Different societies view time differently and as a result this view influences business activities. \\
\hline $\begin{array}{l}\text { Attitudes to the } \\
\text { environment }\end{array}$ & $\begin{array}{l}\text { Differences in societies where some societies view themselves as the drivers of their fate whilst some } \\
\text { societies believe the world to be more powerful than individuals. }\end{array}$ \\
\hline
\end{tabular}

Adapted from: Moran, Abrahamson and Moran (2014).

\subsection{Cultural diversity and the global workforce}

The world of business is becoming increasingly diverse. Globally deteriorating economic conditions, globalization, political fragility and increased mobility of people has resulted in the heterogeneity of the global workforce (Erzébeth, 2012). According Van der Bank and Rothman (2006) and Okpara and Kabongo (2011:1), the increase in globalization has led to more employees being sent on international assignments than ever before and that reliance on expatriate skills will continue to be the trend in the future." Globally organizations now have a diverse labour force due to the effects of globalization. The business interests of multi nationals in foreign countries require expertise well beyond that found in a country itself. Such organizations may have to deploy expatriate experts across countries. In addition the growing expatriate workforce in countries is a result of political and economic uncertainty in resident countries.

The recent economic meltdown and financial crises has forced individuals and organizations to seek prosperity well beyond the boundaries of their countries. Organizations of all sizes are sensitive to the global opportunities and interrelated economy. Chen, Pornoy and Liu, (2012) states that "with the progressive globalization of the workforce, businesses are more and more finding themselves working more often with culturally diverse employees"

According to Van der Bank and Rothman (2006), global assignments are becoming more important for both individuals' careers and companies' global success, having a systematic means to measure expatriate success is increasing in importance. Considering that the Swaziland education sector relies on expat educator skills as well as other cultural diversity elements discussed, it is expected that the Swaziland ministry of education also needs to consider the context of expatriate labour and the factors for successful performance. The value of which is important for the Ministry of Education (MoE) reviews for broad policy and strategy formulation as well as individual educators for individual reflection review and personal development plans.

\subsection{Management and leadership considerations of cultural diversity}

Cultural diversity could negatively influence performance of a team or organization. However, this needs not be the case. When properly managed, the negative effects of cultural diversity in an organisation could be neutralised.

UNESCO (2012) points out that the majority of studies are focussed on globalization tends to focus on changes taking place in the economic and political fields however many questions have been raised over the effect of globalization on the environment and the labour market.

Arising out of this growing sensitivity of the impact of globalization on the labour market in particular cultural diversity, managers and organizational leaders need to be highly in tuned with managing diverse teams. Rene and Van der Linden (2012) advocates that 'Tomorrow's managers will need to learn how to work, function and to compete in such a boundary less and global world, Leaders have an important role in engaging with their employees, it is clear that supervising employees of different cultures is a difficult, complicated matter.' What can be gleaned from this is that the challenge of management and leadership of teams and organizations requires an ability from managers and leaders to 
firstly acknowledge the need to be sensitive to the context as well as a concerted effort to reflect upon their approaches to managing within such a context. Hereunder is an example of a management need in such a context within an educational environment.

Meier and Hartell (2009) says that increasing cultural diversity in educational institutions requires educationists to learn to teach and manage learners within cultures, languages and backgrounds that are unknown to them, Whilst this reasoning refers to the case of teaching and managing tertiary education students, the same constraints are present when working with and managing school level educators. Sturz, Kleiner and Fernandez (2005/6) indicates that the classroom and educational environment is becoming increasingly culturally diverse and that teachers and educational managers need to be aware of such differences, stereotypes, ethnocentrism and prejudices that may prevail and that this awareness needs to re shape the teaching methods, curriculum design and educational settings. The Swaziland education ministry and its management need to be aware of the culturally diverse workforce it utilizes in order to ensure harmonious and productive education provisioning.

This view is strengthened by Meier and Hartell (2009:180-192) who indicates that 'to handle diversity effectively in education, educators need to recognize the validity of differences. One could extrapolate this reasoning to the Swaziland education sector as well considering the social political similarities found in both countries. In particular both Swaziland and South Africa are dealing with the vestiges of a British colonial education past.

According to French (2010:93) management needs to enhance the quality of intercultural communication and crossing the barriers of language differentiation. He advocates that one way of enhancing intercultural communication is to have a thorough awareness of cross cultural differences per se. Theoretically this, view is sound, however, in practice with a large number of employees, the execution or comprehension of all the differences in the working environment proves much more challenging. Managers need to be reflective of cultural differences in their communication, their interpersonal characteristics as well as their general ability to show patience or understanding in a culturally diverse workforce. Thus the approach of "one size fits all" understanding by management is unwise, and it is imperative for management success to include a multi-cultural managerial approach. Irrespective of setting, sector or context the presence of such diversity requires managers to be able to communicate effectively through understanding such nuances, then adjusting personal style and develop skills to ensure two way effective communications.

According to Robbins et al. (2009) cross cultural factors clearly create the potential for increased communication problems. Robbins identified four specific challenges that are related to language difficulties in cross cultural communication. These are barriers caused by:

- semantics;

- word connotations;

- tone differences; and

- barriers caused by differences amongst perceptions.

If these barriers are related to engagement between work colleagues and between different levels in an organizations hierarchy it is clear that the potential for ineffective communication exists. French (2010) adds to Robbins et al (2009) by stating that cultural differences, as manifested through language, are not confined only to vocabulary, but that the structure of a language is also a reflection of culture and serves to reinforce the culture through the expression of its members.

More important though is that managers and leaders should understand the implications of ineffective communication. As a result of the above, ineffective communication may result in stress amongst the role players, poor relationship building and ambiguity which results in poor performance at an individual and organizational level. This then inadvertently influences business and individual satisfaction. Since management views human resources management for the realization of work productivity, creative thinking, and creation of competitive advantage the issue of managing diversity in human resources is an important focus. According to the CIPD's Barometer of Human Resources trends and prospects (Robbins et al., 2009) show that almost $60 \%$ of organizations recognize that effective diversity management makes business sense. This suggests a general awareness of the importance of managing diversity. Inherent in this diversity is the notion of cultural diversity. Considering the impact of globalization and a boundary less business environment, the recognition of the importance to effectively manage diversity should be higher.

A number of publications have been produced on workforce diversity and its positive influence on organizational outcomes. However, there are also situations where diversity poses negative challenges. Chen et al. (2012) state that a multilevel investigation of motivational cultural intelligence, organizational diversity climate and cultural sales studies have shown that workforce diversity has helped companies generate higher earnings, net profits. This supports the view that diversity in whichever form can also be a positive influence. The corollary to this is that diversity in the workforce does not 
automatically ensure positive outcomes (Chen et al., 2012).

Numerous studies have continually demonstrated that, since the eighties, there are negative effects of demographic, psychographic, or cultural diversity on individuals, work teams, and organizations. (Feldman et al., 1980; Shaw, 1983; Tsui, Egen \& O'Reilly, 1992). The above authors cite that the most common negative consequences at the individual and team levels include misperception, miscommunication, increased tension, conflict, mistrust, process loss, and lower psychological commitment.

Managers and leaders are requires a management approach such as to increase the benefits of diversity whilst mitigating the down sides of diversity. McKay, Avery and Morris (2009) (in Chen et al. 2012) mention that a commitment to diversity must be ingrained in the corporate core value system. Organisations that create a positive diversity climate in which employees share the perceptions that their organisation has adopted fair employee policies, positively socially integrates all its personnel successfully through an integrated workforce. Diversity thus may be a positive attribute that may result in organizational competitiveness. What is evident is that managers have to deliberate and ensure concerted efforts to create an organization that has central in its core the willingness towards creating a diversity strategy. An example of congruent discourse is found in French (2010:65) who reasons that in view of the impact of increased flows of labour across the world, a major part of cross cultural management involves effective management of diverse employees. Resultantly, diversity can be used to positive ends, and the value of diversity acts as a positive factor in creating organizational competitiveness,

According to Rijamampianina and Carmichael (2005) cited in Kamal and Ferdousi (2009:158) argue that diversity, if effectively managed, can be a source of competitive advantage for the group or organisation.

Managers and leaders need to be able to recognize the possible advantages and disadvantages of working within a culturally diverse workforce. This shapes the management approach in managing such diversity. Adler (2002) and Kamal and Ferdousi (2009:159) identified three approaches to manage the diversity namely Parochial, Ethnocentric and Synergistic.

Figure 1: Approaches To Managing Diversity

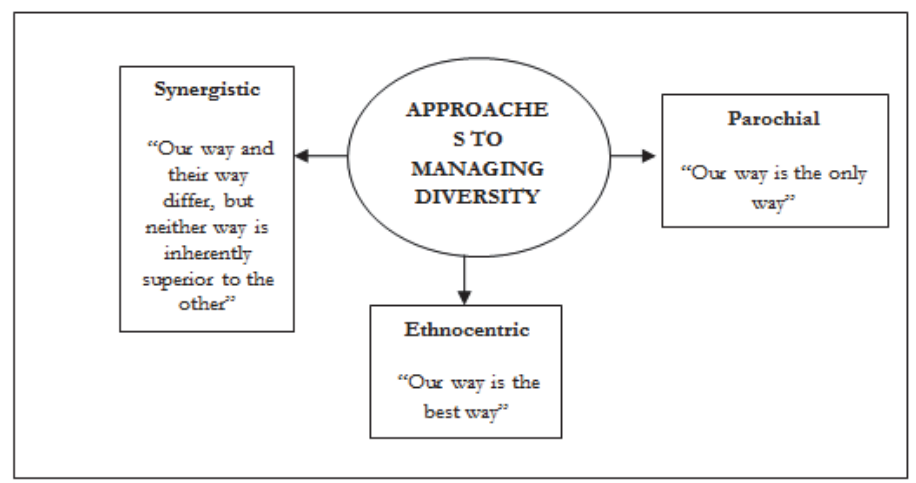

Source: Adapted from Adler (2002) and Ferdousi (2009)

This model's approaches to management focus on three elements or views, namely the:

- Synergistic view - which suggests that there may be different ways but neither is superior to each other. This element considers the differences and similarities in each culture in doing things.

- Ethnocentric view - This view suggests that the best way or best view is from one culture. This view recognises that there exists alternatives but one's own view or way is the best.

- Parochial view - This view negates the possibility of alternative views or ways. It thus rejects that alternatives may exist.

Amaram (2007), in support of the original work by Cox and Blake (1991), suggests that a number of management issues exist with regard to managing cultural diversity in an effort to create a competitive organization. These managerial issues are: (1) Mindsets about diversity, (2) Organisational culture, (3) Human Resurce management systems, (4) Higher career involvement of women, (5) Cultural differences, (6) Education programmes and (7) Heterogeneity in race/ethnicity/nationality. These issues are explained below.

- Issue 1: Mind Sets about Diversity

The mind sets about diversity consist of three subsets, namely: 
- Firstly it frameworks the managerial or organisations view of diversity. For example it defines how management views diversity either as an opportunity or a challenge.

- Secondly it tests the level of attention paid to diversity.

- Thirdly, it suggests a consideration to how much buy in or resistance prevails either by the majority culture or lesser represented cultures is needed.

- Issue 2: Organisational Culture

Organisational culture deals with the level of value placed on differences between cultures and how the organisations approach cultural inclusion.

- Issue 3: Human Resource Management Systems which are Bias Free.

This issue deals with the HR system an organisation uses with regards to recruitment, training and development, performance appraisal. The main point being the system needs to be free of any bias and prejudice in any way.

- Issue 4: Higher Career Involvement of Women

In this issue the situation of women in the workforce signalling the dual role that women play as career women, family responsibility and the challenges endured(such as sexism in the workplace and sexual harassment together with the challenge of balancing work life and family responsibility) are highlighted.

- Issue 5: Cultural Differences

This issue speaks of cultural diversity awareness and sensitisation and how such diversity may yield advantage and success.

- Issue 6: Education Programmes

Issue six deals with the need to improve school education to improve cultural diversity awareness and management education to account for cultural diversity management.

- Issue 7: Heterogeneity in Race/Ethnicity or Nationality.

Here the issues of cohesiveness, communication, conflict and morale is dealt with. It also deals with group identity and inter-group relations, racism, prejudice and ethnocentrism.

The above issues serve as a framework when attempting to understand or approach to management of cultural diversity. Managers may choose to interpret and use different elements of various frameworks and models in an effort to find a useful and practical approach for individual comfort.

Multinational corporations have come increasingly sensitive to the value and place of workforce diversity as an integral element to organisational success. Resultantly it can be gleaned that the issues of cross cultural management and cultural diversity management is increasingly important for overall organisational success.

\section{Research Methodology}

The research methodology consists of both a literature and an empirical study. The literature study focuses on cultural diversity. The literature study included textbooks, newspaper articles, government publications, conference proceedings as well as internet surveys. The university libraries of the North-West University and Regent Business School were used to source reference materials.

\subsection{Data collection}

The empirical study profiled the educators in this study. Data was collected using the ASSET questionnaire (An Organisational Stress Screening Tool), developed by Cartwright and Cooper (2002) as an initial screening tool to help organisations assess the risk of occupational stress in their workforce (Naido0, 2011:15). This questionnaire proved to be a valid and reliable tool in similar educational research (Naidoo, 2011; Jackson, 2004; Jackson \& Rothman, 2006; and Van Wyk, 2006). This questionnaire was distributed, using a stratified sample of state schools, to Swaziland educators, and the principal supervised the completion and collection of the questionnaires. The questionnaire also measured demographic and biographic variables of educators in schools.

The questionnaire was only administered to government schools to ensure that the sample group is representative of only government schools because private schools are structured differently, funded and governed differently as well as serve a different population group as to those served by government schools. Whilst the regulatory requirements that govern government schools also govern private schools the educator profile, education, training and philosophy is different as many are religious based schools or schools that are part of an international model of schooling. The researcher collected the completed questionnaires from the principals. The study had the permission and blessing of the 
Swaziland Ministry of Education who assisted in facilitating and coordination of the distribution and retrieval of questionnaires. A total of 550 questionnaires were distributed, and 377 completed questionnaires were received. This signified a satisfactory response rate of $68.5 \%$.

\subsection{Statistics employed}

The empirical results for this article are presented in accordance to themes as per the questionnaire used (see Appendix A). Exploratory Factor Analyses (EFA) with a Varimax orthogonal rotation of the axis was used to identify cultural diversity factors to manage in Swaziland's public schools (Field, 2007:749).

Before the factor analyses was undertaken the data was subjected to the Kaiser Meyer Olkin (KMO) measure of sampling adequacy and the Bartletts test of spehericity to ensure that the sample was appropriate and that the data is suitable for EFA analyses (Field, 2007:668).

According to Du Plessis (2009:26), KMO values of at least 0.6 should be present before advanced statistical analysis considered based on an adequate sample criterion. Usually values below 0.5 are unacceptable while values of 0.7 and higher are regarded signify an adequate sample fit for advanced statistical analysis (Field, 2007:640 in support of research by Hutcheson and Sofroniou, 1999). These authors also point out that values between 0.7 and 0.8 are regarded as "good" while values between 0.8 and 0.9 are "excellent". Values between 0.9 and 1 are "superb". A value close to 1 suggests that sample used is adequate and should yield usable results. This study set a KMO value at a minimum of 0.70 as suggested by Field (2007:672).

Bartlett's test of sphericity is used to test the null hypothesis that the variables in the population correlation matrix are uncorrelated (Coakes, Steed \& Price, 2008). The acceptable significance level is equal or below .005 (Field, 2007:641). If the data value is below 0.005 , then the data is suitable for the purposes of multivariate statistical analysis such as factor analysis because the intercorrelations between the variables are low and would not influence the results negatively (Du Plessis, 2009:58).

The Cronbach alpha was also calculated to determine the reliability and the internal consistency of the data (Wuensch, 2009:58). For this study the minimum Alpha coefficient is set at 0.70 (Field, 2007:668).

\section{Results}

\subsection{KMO and Bartlett's Test}

The adequacy of the sample was measured by employing KMO measure of sampling adequacy. In addition, to determine the suitability to continue towards exploratory factor analysis, the inter-relationships exist between the variables were calculated by means of Bartlett's test of sphericity. Table 3 presents the results:

Table 3: The Kmo And Bartlett's Test

\begin{tabular}{|cc|c|}
\hline \multicolumn{2}{|c|}{ Kaiser-Meyer-Olkin Measure of Sampling Adequacy. } & .704 \\
& Approx. Chi-Square & 724.311 \\
Bartlett's Test of Sphericity & $\mathrm{df}$ & 105 \\
& Sig. & .000 \\
\hline
\end{tabular}

The analysis showed that the sample is adequate. The sphericity assumption was tested using the Bartlett test and the Kaiser-Meyer Olkin (KMO) was used to measure sample adequacy. The result arising from these two tests are found in table below. The KMO measure returns a satisfactory value of .704. The Bartletts test of sphericity returns a favourable value of .000 (which is less that the required value of 0.05 ). This denotes sufficient inter-variable relationships for conducting the factor analysis.

\subsection{Exploratory factor analysis}

The exploratory factor analysis identified five factors. An orthogonal Varimax rotation was employed to do so. Varimax was selected as rotational method because it attempts to maximise the dispersion of factor loadings by loading a smaller number of variables highly onto each factor resulting in a more interpretable cluster of factors (Field, 2007:749). Only 
factor loadings that were equal or higher than 0.40 were considered to be significant and were used in the analysis, while factors with Eigenvalues of 1 and higher were extracted from the matrix (Mutambara 2013:115). The five factors extracted from the analysis as well as the pertaining statements that loaded onto these factors are shown in Table 4 . The five factors explain a cumulative variance of $55.11 \%$.

Table 4: Factor Loadings: Perceptions of Organisational Politics

\begin{tabular}{|c|c|c|c|c|c|}
\hline \multirow{2}{*}{ Criteria } & \multicolumn{5}{|c|}{ Components } \\
\cline { 2 - 6 } & Factor 1 & Factor 2 & Factor 3 & Factor 4 & Factor 5 \\
\hline $\mathrm{q} 52$ & .808 & & & & \\
$\mathrm{q} 53$ & .711 & & & & \\
$\mathrm{q} 23$ & .673 & & & & \\
$\mathrm{q} 24$ & .624 & & & & \\
$\mathrm{q} 69$ & -.507 & .745 & & & \\
$\mathrm{q} 61$ & & .600 & & & \\
$\mathrm{q} 43$ & & .561 & & & \\
$\mathrm{q} 60$ & & .531 & & & \\
$\mathrm{q} 36$ & & .458 & -.802 & & \\
$\mathrm{q} 26$ & & & -.585 & & \\
$\mathrm{q} 65$ & & & & .585 & \\
$\mathrm{q} 25$ & & & & & \\
$\mathrm{q} 45$ & & & & & \\
$\mathrm{q} 47$ & & & & & \\
$\mathrm{q} 42$ & & & & & \\
\hline
\end{tabular}

\subsubsection{Factor 1: Cultural Bias}

A total of five statements loaded on factor 1 . These statements are numbers $52,53,23,24$, and 69 . Statements 23 and 24 deal with the unfair distribution of resources based on race and cultural groups, while statements 23 and 24 deal with the objectives of similar values despite the fact that cultures differ. Statement 69 states that mutual respect exists between different cultural groups. Noteworthy is the fact that statement 69 has a negative factor loading. This means that the respondents have identified mutual respect as important issue, but they perceived this concept to be the inverse, namely that disrespect exists between the different cultural groups.

As mentioned earlier cultural diversity in the workplace has become common. Resultantly, managers need to be aware of such diversity and able to manage such cultural diversities to ensure the yielding of maximum team and organizational performance. Cultural diversity if not managed can be a double edged sword according to Kirkman and Shapiro (2005). These authors indicate that if team members have different conceptional understanding of teams itself it gives rise to possible conflict in thought and understanding. All these items deals with cultural bias, how culture differences should not be dealt with. Therefore, the factor was labelled as Cultural Bias. The factor explains a variance of $18.01 \%$.

\subsubsection{Factor 2: Cultural Tolerance}

Five statements loaded on this factor. These statements are 61, 43, 60, 36 and 26. Statements 61 loaded a high .745 which suggests that there exists a culturally diverse environment in the Swaziland education sector. According to Von Bergen and Massey (2013) tolerance has been historically viewed as a concept of a permissive practice of allowing things that one disapproves off; in an effort to coexist with others who are different or behave differently. It's almost as if people would 'put up' with people or things that one is not generally accepting off. However, the adapted definition by UNESCO in 1995 has changed the historic views reported on by Von Bergen and Massey (2013) because UNESCO redefined tolerance according to the principles of respect, acceptance and an appreciation of diversity of world cultures. As a result tolerance is viewed as an expression of being human and that there needs to be transparency and a conscientious effort to learn and express freedom of thought. Importantly it does not allow for tolerance to be regarded as a moral duty but as a concept that allows harmonious co-existence in a culturally plural society where everyone is responsible and that no parties' human rights are infringed upon. Statement 43 has a strong loading of .60 suggesting that there is a belief that cultural diversity should be retained. 
Statement 26 loaded lower at .458 which could be interpreted as a feeling that there is no need for more learning about different cultures. The central them that permeates Factor 2 are that of cultural tolerance thus the title of cultural tolerance. The variance explained by the factor is $13.93 \%$

\subsubsection{Factor 3: Cultural Association}

Two statements loaded onto this factor. These are statements 25 and 65 . Both these statements have yielded a negative loading of -.585 and -.802 respectively. Statement 25 deals with individual perception that co-workers are familiar or not familiar of the diverse work force and item 65 deals with the ability to communicate comfortably with unfamiliar members of the same culture. This essentially suggest through a good negative loading that respondents agree that they are able to communicate comfortably with people they are not familiar with but of the same cultural group and that they perceive their colleagues to be sensitive and aware of the culturally diverse workforce. Both statements deal with the issue of relationship and association within different cultures which has resulted in the factor being titled Cultural Association. The variance explained by the factor is $8.69 \%$

\subsubsection{Factor 4: Cultural Inequality}

Two statements loaded onto factor 4. These are statements 45 and 47 . Both these statements deal with equality in treatment of co-workers by co-workers themselves and perception of preferential treatment for certain cultural groups for better opportunities and promotions. Item 45 loaded a high .785 and statements 47 loaded a good .543. Statement 45 suggests that respondents feel that co-workers are not generally treated equally in the workplace. Statement 47 suggests that respondents feel that there exists preferential treatment for some cultural groups over others when dealing with promotions and opportunities in the workplace. Both items speak of the concept of the perception of cultural inequality thus the factor title of cultural inequality. The variance explained by the factor is $7.49 \%$

\subsubsection{Factor 5: Cultural minorities}

This factor consists of one highly loading statement. This is statement 42 which deals with the belief that cultural minorities should be assisted to preserve their heritage. Although only one statement loaded, the high factor loading of 0.84 cannot be disregarded. The statement deals with cultural minorities, and as a result, the factor is labelled Cultural minorities. The factor explains a variance of $6.99 \%$

The five factors explain a cumulative variance of 55.11. The factors and their labels are contextualised in Table 5 below.

Table 5: Factor Labels And Contextualization

\begin{tabular}{|c|l|l|}
\hline Factor & Factor label & Factor refers to: \\
\hline F1 & Cultural Bias & The levels or existence of cultural biasness \\
\hline F2 & Cultural Tolerance & Tolerance levels between cultures \\
\hline F3 & Cultural Association & The amount, nature and quality of interaction between people of different cultures \\
\hline F4 & Cultural Inequality & The perception of inequality and preferential treatment amongst different cultures \\
\hline F5 & Cultural Minorities & The situation of minority cultures. \\
\hline
\end{tabular}

\subsection{Reliability}

The reliability of the five factors was calculated using the Cronbach Alpha coefficient. The results appear in Table 3.3. The required coefficient of 0.7 set was not achieved as the minimum level of reliability in this study. 
Table 6: Reliability of the Factors

\begin{tabular}{|c|c|}
\hline Data Sets & Cronbach's Alpha \\
\hline Factor 1 & 0.494 \\
\hline Factor 2 & 0.555 \\
\hline Factor 3 & 0.420 \\
\hline Factor 4 & 0.196 \\
\hline Factor 5 & $\star \star \star$ \\
\hline
\end{tabular}

From the table it is clear that the factors cannot be regarded as highly reliable. Field (2007:675), however, states that alpha coefficients of 0.57 (based on extensive research by Cortina, 1993 on reliability) could also be regarded as reliable. However, even the lower coefficient is not reached by the factors, and despite of acceptable sample adequacy and spericity, none of the factors have acceptable reliability coefficients. In practice, the lower reliability levels do not influence their importance of the factors to the current study (Naidoo, 2011). However, it heeds a warning that a low reliability coefficient indicates that if the study were to be repeated in a different application setting, these factors are less likely to represent themselves.

\subsection{Correlation analysis}

The correlations between the identified factors have been calculated by means of Pearson's Correlation Coefficients. These correlations appear in Table 3.7 below.

Table 3.7: Factor Correlations

\begin{tabular}{|c|c|c|c|c|c|}
\hline Factor & 1 & 2 & 3 & 4 & 5 \\
\hline 1 & 1.000 & .025 & -.126 & .188 & .031 \\
2 & .025 & 1.000 & -.091 & .099 & .143 \\
3 & -.126 & -.091 & 1.000 & -.102 & -.030 \\
4 & .188 & .099 & -.102 & 1.000 & .101 \\
5 & .031 & .143 & -.030 & .101 & 1.000 \\
\hline
\end{tabular}

From Table 3.7 it is clear that no strong correlations (>0.5) exist between the five factors (Field, 2007:220). This means that the factors can be viewed as separate constructs and that managerial interventions between the factors are not interrelated. This means in practice that a managerial intervention on one factor would not have a positive or negative influence on any of the other factors. Each factor should thus be managed as separate entity.

\section{Discussion and Recommendations}

The analysis revealed that five factors (independent of one another) were identified as cultural diversity constructs that could be managed to improve in Swaziland education. In this regards research by Seymen (2006) found that active management of cultural diversity creates an organisational environment that allows all the employees to reach their full potential in pursuing the organisational goals. Evidently the Swazi school education sector consists of a diverse workforce. There are a number of considerations for Swazi School education managers and leaders. Following is an explanation of some of considerations for the improvement of cultural diversity management in Swaziland school education sector.

The research results identify five factors that influence the management of cultural diversity in the Swaziland school education environment. These are, in the order of importance: Cultural Bias, Cultural Tolerance, Cultural Association, Cultural inequality and Cultural minorities.

The results suggests that there exists a degree of perception amongst educators is Swaziland that cultural bias is prevalent in the education environment. Further a strong perception that there exists cultural inequality amongst educators. The management should consider its position on how it views such employee perceptions. Not managing such cultural diversity factors effectively does not bode well for individual performance and overall organizational effectiveness. The management of the Swaziland education system is further required to consider a strategy to ensure that these cultural bias factors are being interrogated and its risks mitigated. The strategy considered must take into account the 
factors that are creating the levels of cultural bias. The two main factors of resources being allocated on the basis of race as well as the reservation of top management positions for a specific cultural group can be remedied with proper and transparent policies on resource allocation and comprehensive inclusive career mapping policies ad plans.

These initiatives will create a more structured understanding of career mapping opportunities as well as clarity of how resources are allocated from a policy perspective. From the literature review it is evident that if there exists such a degree of "unhappiness" then it will certainly affect individual educator performance which in turn will affect the success of the educational provisioning in the Swaziland education sector.

The issue of cultural tolerance loaded highly indicating that there exists a cultural diversity in the education environment. With reference to the framework for managing cultural diversity adapted from Cox and Blake (1991) a number of guidelines may be pursued in this regard to raise the awareness and comfort levels amongst Swaziland educators who have a perception that there exists a degree of cultural intolerance attitude in the workplace or environment. Central to this is management efforts in putting in place programmes to enhance awareness and provide opportunities for relationship building. This is particularly necessary as the education labour force is rapidly changing due to the high number of expatriate educators entering the education system. As a mid-term strategy the education ministry may consider various efforts to prevent any negativity in the increasingly diverse education labour force in Swaziland. It is good management planning to also acknowledge what is working or is positive and healthy within the diversity factors and ensure adequate effort is made to continue the positive status. It is imperative that management does not only focus on the areas of improvement and in doing so fails to continue the efforts in addressing the factors that are least influential.

Importantly cultural diversity needs to be a celebrated notion and approached as a positive element of the labour force. Staff and team building exercises will help create an awareness and sensitivity to the value of collaborative team work.

\section{Summary}

The literature review shows clearly the rapidly changing make-up of the global workforce. This change is primarily being driven by the forces of globalisation. The trend of mass exodus of workers, mobility of workers as well as the increasingly virtual reality of the world of work is to continue into the future. Managers will be required to manage culturally diverse teams in the virtual work environment where workers working on the same project or task will not necessary be in direct face to face contact with each other.

Inherent in the workforce is the element of cultural diversity. The Swaziland School Education Environment is in itself a culturally diverse environment. Effective managerial approaches to manage and lead a culturally diverse workforce are critical for overall success. Having the emotional intelligence required to recognise nuances existing on a culturally diverse workforce is important.

\section{References}

Adler N.J., \& Gundersen, A. (2008). International Dimensions of Organisational Behaviour. $5^{\text {th }}$ ed. New York: Thomson.

Amaram, D.I. (2007). Cultural Diversity: Implications for Workplace Management. Journal of Diversity Management, 2(4), 1-6.

Bolen, L., \& Kleiner, B.H. (1996). Managing diversity in the workplace. Cross Cultural Management: An International Journal, 3(4), 3-8.

Chen, X.P., Portnoy, R., \& Liu, Y. (2010). Cross-cultural management in China. Cross Cultural Management: An International Journal, $17(3), 223-243$.

Chen, X.P., Portnoy, R., \& Liu, Y. (2012). A Multilevel Investigation of Motivational Cultural Intelligence, Organizational Diversity Climate, and Cultural Sales: Evidence From U.S. Real Estate Firms. Journal of Applied Psychology, 97(1), 93-106

Coakes, S.J., Steed, L.G. \& Price, J.C. (2008). SPSS: Analysis without anguish. Perth: Wiley.

Cox, T. (1993). Cultural diversity in organizations: theory, research and practice. New York: Berrett-Koehler.

Cox, T.H., \& Blake, S. (1991). Managing cultural diversity: implications for organizational competitiveness. Academy of Management Executive, 5(3), 45-46.

Dlamini, S. (2013). Personal Interview. Deputy Director General of Education in Swaziland. Swaziland.

Drafke, M.W., \& Kossen, S. (2002). The humans Side of Organisations. New Delhi: Prentice Hall of India.

Du Plessis, J.L., (2010). Statistical consultation services. Department of Statistical Consultation Services, North-West University, Potchefstroom.

Dunmark, L. (2005). How to deal With Cultural Differences as a Project Manager. Journal of Contemporary Management, 2(1), 81-97.

Erzsébet, M. (2012). Global cultures? Consequences of globalization on cultural differences: a commentary approach. International Journal of Business Insights and Transformation, 5(3), 94-100.

Feldman, J.M., Sam, I.A., McDonald, W.F., \& Bechtel, G.G. (1980). Work outcome preference and evaluation: A study of three ethnic groups. Journal of Cross-Cultural Psychology, 11, $444-468$. 
Field, A. (2007). Discovering statistics using SPSS. $2^{\text {nd }}$ ed. London: Sage.

French, R. (2010). Cross-cultural management in work organisations. $2^{\text {nd }}$ ed. London: CIPD.

Hamid, Y. (2014). Culture and corruption. International Journal of Development Issues, 13(1), 5-21.

Holden, R. (2000). Managing people's values and perceptions in multi-cultural organizations: The experience of an HR Director. Employee Relations, 23(6), 614-626.

Huettinger, M. (2008). Cultural dimensions in business life: Hofstede's indices for Latvia and Lithuania. Baltic Journal of Management, 3(3), 359-356.

Hutcheson, G.D., \& Sofroniou, N. 1999. The multivariate social scientist. $4^{\text {th }}$ ed. New Delhi: Sage.

Jackson, L.T.B. 2004. An adapted model of burnout for teachers in South Africa. (Thesis - PhD). Potchefstroom: Potchefstroom University for Christian Higher Education.

Jackson, L.T.B. \& Rothmann, S. 2006. Occupational stress, organisational commitment and ill-health of educators in the North West Province. South African Journal of Education, 26(1), 75-95.

Kamal, Y., \& Ferdousi, M.M. (2009). Managing Diversity at Workplace: A Case Study of hp. ASA University Review, 3(2), 156-160.

Kirkman, B.L. \& Shapiro, D.L. (2005). The impact of cultural value diversity on multicultural team performance. Advances in International Management, 18(18), 33-67.

Lewis, M.P., Simons, G., \& Fennig, C.D. (2014). Languages of the world. [Online] Available: http://www.Fennig.com/country/ sz/languages. (30 Aug. 2014.)

Meier, C. \& Hartell C. (2009). Handling cultural diversity in education in South Africa. South African Education Journal, 6(2), 180-192.

Moran, R.T., Abrahamson, N.R., \& Moran, S.V. (2014). Managing Cultural Differences. New York: Routledge.

Mullins, L.J. (2010). Management and Organisational Behaviour. 9th ed. London: Pearson Education.

Mutambara, E. (2013). Perceptions of organisational politics and its impact on managerial practices: national electricity provider in the SADC community. Potchefstroom: NWU. (Thesis - PhD)

Naidoo, K. (2011). Stress management and its impact on work performance of educators in public schools in KwaZulu-Natal. (Thesis PhD). Potchefstroom: North-West University

Okpara, J.O., \& Kabongo, J.D. (2011). Cross-cultural training and expatriate adjustment: A study of western expatriates in Nigeria. Journal of World Business, 46, 22-30.

Oxford Dictionaries. (2014). Oxford Online. [Online] Available: Oxforddictionaries.com/definition/english/cultural-diversity (Aug 14, 2014).

Rene, S., \& Van der Linden, K. (2012). The influence of cultural intelligence of the supervisor and the cultural similarity between supervisor and employee on employee engagement. Management Today, 29(10), 63-66.

Rijamampianina, R., \& Maxwell, T. (2002). Towards a more scientific way of studying multicultural management. South African Journal of Business Management, 33(3), 17-26.

Robbins, S.P., Roodt, G., Judge, T.A., \& Odendaal, A. (2009). Organisational behaviour global and Southern African perspectives. $2^{\text {nd }}$ ed. Cape Town: Pearson Education.

Seymen, O.A. (2006). The cultural diversity phenomenon in organisations and different approaches for effective cultural diversity management: a literary review. Cross Cultural Management: An International Journal, 13(4), 296-315.

Shaw, M. E. (1983). Group dynamics: The psychology of small group behavior. New York: McGraw-Hill.

Sturz, B.H., Kleiner, D., \& Fernandez, A.F. (2005/6). Effective Management of Cultural Diversity in a Class room Setting. Equal Opportunities International, 24(5), 57-64.

Tervonen, K. (2012). The role of diversity management in human resource management in hotel business. Saimaa University of Applied Sciences. (Master's thesis).

Tsui, A.S., Egan, T. D., \& O'Reilly, C. A. (1992). Being different: Relational demography and organizational attachment. Administrative Science Quarterly, 37, 549-579.

UNESCO (United Nations Educational and Scientific Organisation). (1995). Declaration of Principles on Tolerance. [Online] Available: http://www.unesco.org/webworld/ peace_library/UNESCO/HRIGHTS/124-129.HTM (Feb. 7, 2014).

UNESCO. 2012. Unesco Institute for Statistics. [Online] Available: http://www.uis.unesco.org/culture/Documents/FCS-handbook-1economic-contribution-culture-en-web.pdf (Aug 30, 2014).

Van de Bank, M., \& Rothman, S. (2006). Correlates of expatriates cross cultural adjustment. Management Dynamics, 15(4), 29-31.

Van Wyk, D. 2006. Work wellness among secondary school teachers in the Goldfields region of the Free State Province. (Thesis - PhD). Potchefstroom: Potchefstroom University.

Vidhi, A. (2012). Managing the diversified team: challenges and strategies for improving performance. Team Performance Management: An International Journal, 18(7/8):1-19.

Von Bergen, C.W., \& Massey, J. (2013). Misconstrued tolerance: issues for multicultural and diversity training. Development and Learning in Organizations, 27(2), 9-12.

Wuensch, K.I. (2009). Factor analysis - SPSS. FA-SPSS doc. SPSS Help Index. Version 17. [Online] Available: http://spss.com/ software/statistics (Jan. 12, 2014). 